\title{
NOKTA BULUTU VERİII İLE KURAL TABANLI AÇIK KAPI BULMA YÖNTEMİ
}

\author{
Burak KALECI'1* ${ }^{*}$ Kaya TURGUT² \\ ${ }^{1}$ Eskişehir Osmangazi Üniversitesi, Mühendislik Mimarlık Fakültesi, Elektrik Elektronik Mühendisliği Bölümü, \\ Eskişehir, ORCID No : http://orcid.org/0000-0002-2001-3381 \\ 2 Eskişehir Osmangazi Üniversitesi, Mühendislik Mimarlık Fakültesi, Elektrik Elektronik Mühendisliği Bölümü, \\ Eskişehir, ORCID No : http://orcid.org/0000-0003-3345-9339
}

\begin{tabular}{|c|c|}
\hline Anahtar Kelimeler & Öz \\
\hline $\begin{array}{l}\text { Açık Kapı Bulma } \\
\text { Nokta Bulutu Verisi } \\
\text { Kural Tabanlı } \\
\text { GAZEBO }\end{array}$ & $\begin{array}{l}\text { Bina içi ortamlarda kapı konumlarının belirlenmesi problemi, konumlandırma, } \\
\text { seyrüsefer, anlamsal sınıflandırma, yapı bilgi modellemesi ve otonom tekerlekli araç } \\
\text { gibi çok farklı uygulamalarda ele alınmaktadır. Geçmiş çalışmalarda bu konu ile ilgili } \\
\text { çözüm sunan yöntemler genellikle görsel bilgi ile kapalı kapıları ya da mesafe bilgisi ile } \\
\text { açık kapıları belirlemeye çalışmışlardır. Son yıllarda nokta bulutu verisi ve/veya } \\
\text { derinlik imgesi üretebilen algılayıcıların robotik alanında kullanılması ile birlikte bu } \\
\text { veri kullanılarak kapı konumu belirlemeye çalışan yöntemler de geliştirilmistir. Bu } \\
\text { çalışmanın temel amacı bina içi ortamlarda nokta bulutu verisi kullanarak açık kapı } \\
\text { konumunu gerçek zamanlı olarak tespit edebilecek bir yöntem sunmaktır. Bu yöntemde } \\
\text { ilk olarak robotun yerel koordinat sistemine göre elde edilen nokta bulutu, küresel bir } \\
\text { koordinat sistemine aktarılmaktadır. Daha sonra küresel koordinat sistemini temel } \\
\text { alarak açı kapı konumunun tespiti için bir dizi kural tanımlamaktadır. Önerilen } \\
\text { yöntemin verimliliğini ölçmek amacıyla GAZEBO benzetim ortamında, robotun açık } \\
\text { kapı konumunu farklı açılardan gördügüü durumlar için elde edilen nokta bulutu verisi } \\
\text { ile "OGUROB KAPI" veri kümesi oluşturulmuştur. Bu veri kümesi üzerinde yapılan } \\
\text { testler kapı bulma başarısı ve süresi açısından incelenmiştir. Test sonuçları önerilen } \\
\text { yöntem ile ortalama kapı bulma süresinin 10ms olduğunu göstermiştir. Ayrıca, kapı } \\
\text { bulma doğru pozitiforanının \%91 olduğu gözlemlenmiștir. }\end{array}$ \\
\hline
\end{tabular}

RULE-BASED OPEN-DOOR DETECTION METHOD WITH POINT CLOUD DATA

\begin{tabular}{ll} 
Keywords & Abstract \\
\hline Open-Door Detection & In indoor environments, the door detection problem is addressed in many different \\
Point Cloud Data & applications such as localization, navigation, semantic classification, building \\
Rule-Based & information modeling and autonomous wheeled vehicle. In previous studies, the \\
GAZEBO & methods, which handle door detection problem, generally tried to identify closed-doors \\
& and open-doors via visual and range information, respectively. In recent years, with the \\
& use of sensors that can generate point cloud data and/or depth image in the robotic \\
& applications, the methods that attempt to determine the door position with that data \\
& have also been developed. The main purpose of this study is to introduce a method that \\
& can detect open-door location in real-time through point cloud data in indoor \\
& environments. Firstly, the point cloud captured according to the robot's local \\
& coordinate system is transferred into a global coordinate system. Then, a set of rules \\
based on the global coordinate system is defined to detect open-door location. "OGUROB \\
KAPI" dataset is constructed to measure the effectiveness of the proposed method. The \\
dataset contains point cloud data gathered in GAZEBO simulation environment for \\
different angles between robot and open- door location. The tests performed on this \\
dataset were examined in terms of the door detection success and the elapsed time. The \\
test results showed that the average door detection time was 10ms with the proposed \\
method. In addition, it has been observed that the true positive rate is $91 \%$.
\end{tabular}

\footnotetext{
*Sorumlu yazar; e-posta : burakaleci@gmail.com
} 


\section{Giriş}

Robotik uygulamalarında kapı konumlarının belirlenmesi problemi uzun yıllardan beri çalıșılan ve hala aktif olarak gündemde olan konulardan biridir. Bunun temel sebeplerinden birisi kapı konumlarının bina içi ortamlarda geçiş noktası olmasıdır. Böylece kapı konumlarının belirlenmesi robotların otonomluk seviyelerine önemli katkıda bulunmaktadır. Bunlara ek olarak, kapı konumlarının belirlenmesi, konumlandırma probleminde kapıların ayırt edici özellik olarak kullanılarak hataların azaltılması, seyrüsefer görevlerine yardımcı olan yol haritalarının oluşturulması, anlamsal harita oluştururken oda ve koridor sınıflarının ayırt edilmesi, otonom tekerlekli sandalye ve yapı bilgi modellemesi gibi çok geniş bir spektrumda bulunan uygulamalarda ele alınmaktadır.

Kapı konumlarının belirlenmesi ile ilgili geçmiş çalışmalar genellikle kapıların açık ya da kapalı olması durumlarını incelemiştir. Bu yöntemler kullanılan algılayıcıya bağlı olarak çeșitlilik göstermekte ve bu kriterler göz önünde bulundurularak 3 temel kategoriye ayrılmaktadır. İlk kategorideki çalışmalar görsel bilgi kullanarak kapalı kapıların bulunmasını amaçlamaktadırlar. Bu çalışmaların iki temel olumsuz yönü bulunmaktadır. İlk olarak piksel tabanlı çözümler önerdikleri için robot ile kapı konumu arasındaki açı ve mesafeden önemli ölçüde etkilenmektedirler ve genellikle başarılı olabilmeleri için robotun kapının tam karşısında olması gerekmektedir. Buna ek olarak, komșu piksellerdeki renk bilgisi arasındaki benzerliği kullanarak kapıların konumlarını belirlemeye çalıştıkları için ortamdaki ışık miktarı bu çalışmaların başarı oranlarını önemli ölçüde etkilemektedir (Yang ve Tian, 2010; Murillo, Košecká, Guerrero ve Sagüés, 2008). İkinci kategorideki çalışmalar ise mesafe algılayıcılardan elde ettikleri bilgileri kullanarak açık kapıları tespit etmeye çalışmaktadırlar. Bu çalışmalarda robot kapı çerçevesinin içinde ya da çok yakınında yer almakta ve kapının genişliği kadar olabilecek bir boşluk tespit etmeye çalışmaktadır (ElKaissi, Elgamel, Bayoumi ve Zavidovique, 2006). Bu çalışmaların temel dezavantajı ise yanlış negatif oranlarının yüksek olmasıdır. Kaleci, Şenler, Dutagaci ve Parlaktuna (2015) yaptıkları çalıșmada yanlıș negatif oranını azaltmak amaciyla robotun kapı çerçevesinin içinde olduğunda lazer ölçümlerinin oluşturduğu darboğaz karakteristiği tespit eden kural tabanlı bir çalıșma önermişlerdir. Geçmiş çalıșmalarda hem mesafe hem de görsel bilgi kullanarak kapı konumlarını belirlemeye çalışan yöntemler de bulunmaktadır (Hensler, Blaich ve Bittel, 2010; Meeussen, Wise, Glaser ve Chitta, 2010). Son kategorideki çalışmalar ise son yllarda robotik uygulamalarda sıklıkla kullanılan 3B nokta bulutu ve/veya derinlik imgesi bilgileri ile açık, yarı açık ve kapalı kapıların konumlarını belirlemeye çalışmaktadırlar. Bu kategorideki geçmiş çalışmalar Bölüm 2'de detaylı olarak incelenecektir.

Önerilen çalışmada, açık kapı konumlarının belirlenmesinde nokta bulutu verisinden yararlanılacaktır. Bunun en önemli sebebi kapı konumlarının robotun kapıdan uzak olduğu durumlarda önceden belirlenmesi ile elde edilen bilginin yol planlaması ve seyrüsefer gibi görevlerde kullanılmasının amaçlanmasıdır. Bu çalışmada, RGB-D kamera kullanılarak düzenli yapıdaki nokta buluntuları elde edilmiştir. Ancak, önerilen yöntem düzensiz yapıdaki nokta bulutu verileri için de kolaylıkla genelleştirilebilir. Kapı konumlarının belirlenmesi için ilk olarak robotun yerel koordinat sistemine göre elde edilen nokta bulutu verisi robotun yönelim açısı kullanılarak küresel bir koordinat sistemine aktarılmaktadır. Daha sonra nokta bulutu içerisinde kameranın ölçüm alamadığı noktaların komşuları kullanılarak bir başlangıç noktası belirlenmektedir. Bu nokta kapıya ait olan ilk köşe noktası olarak kabul edilmektedir. $\mathrm{Bu}$ köșe noktasından başlayarak kapı çerçevesinin geometrik özellikleri ve küresel koordinat sistemi göz önünde bulundurulup kural tabanlı bir arama ile kapıya ait 3 köşe noktası daha belirlenmektedir. $\mathrm{Bu} 4$ köşe noktası kullanılarak yükseklik ve genişlik ölçütlerini hesaplanmakta ve (TS 9111, 2020)' de yer alan standart kapı ölçütleri ile karşılaştırılmaktadır. Eğer genişlik ve yükseklik standartlara uygun ise kapı konumu belirlenmiş olarak kabul edilmektedir. Önerilen yöntemin basit olmasına karșın robot üzerinde gerçek zamanlı çalıșabilen ve yüksek kapı bulma oranları elde edebilen bir yaklaşım olduğu test sonuçları ile gösterilmiştir.

$\mathrm{Bu}$ çalışmanın organizasyonu şu şekilde yapılmıştır: Bölüm 2'de nokta bulutu ve/veya derinlik imgesi bilgileri ile kapı konumu belirleme konusundaki geçmiş çalışmalar irdelenecektir. Bölüm 3'te önerilen kural tabanlı yöntem anlatılacaktır. Yöntemin test edilmesinde kullanılan "OGUROB KAPI" veri kümesi Bölüm 4'te tanıtılmaktadır. Testler sonucunda elde edilen kapı bulma başarısı ve süresi Bölüm 5'te verilecektir. Son olarak, sonuçlar ve gelecek çalışmalar sunulacaktır.

\section{Geçmiş Çalışmalar}

3B nokta verisi ile yapılan bazı çalışmalar derinlik ve renk bilgisini birleștirerek kapı konumunu belirlemeyi amaçlamaktadırlar (Quintana, Prieto, Adán ve Bosché, 2018; Kakillioglu, Ozcan ve Velipasalar, 2016). Quintana ve diğ. (2018) tarafından önerilen yöntem açık, yarı açık ve kapalı kapılar için çözüm sunulmuştur. Açık kapıların bulunması için 3B lazer ile elde edilen nokta bulutunu voksel yapısını aktarmaktadırlar. Bu yapı kullanılarak nokta bulutu zemin, duvar ve tavan olarak bölütlenmektedir. Ayrıca vokseller dolu ya da boş olma durumlarına göre farklı 
etiketlenmektedirler. Açık kapıların tespiti için duvarlardaki boş olarak etiketlenen vokseller incelenmektedir. Eğer duvarlarda açık kapı ile ilgili olan boş vokseller bulunamaz ise algoritma kapalı kapılar için çalışmaya başlamaktadır. Bu noktada, kapalı kapılar için renk ve derinlik bilgileri kullanılmaktadır. Ancak ışık miktarına bağlı olarak yöntemin başarısının etkilenmemesi için ön işlem aşaması gerekmektedir. Genelde kapalı kapılar ile yapılan testlerde \%98,3 kapı bulma başarısı elde etmişlerdir. Derinlik ve renk bilgisini birlikte kullanan başka bir çalışmada Kakillioglu ve diğ. (2016) ise derinlik ölçümü bulunmayan noktalar açık kapı olarak tanımlanırken yanlış negatif oranlarını azaltmak için ise renk bilgisi kullanılmaktadır. Duvar düzlemine ait noktalar üzerinde histogram alınarak en geniş kapı adayı bulunur. Kapıya ait renk bilgisi üzerinden bütünlenmiş kanal özellikleri (Aggregate Channel Feature) çıkarılarak eğitilen model ile kapı adayı için doğrulama yapılmaktadır. Bu çalışmada, yazarlar kapıları ortalama olarak \%86 başarı oranı ile $25,8 \mathrm{~ms}$ sürede bulabilmektedirler. Nokta bulutundan duvar düzlemleri ayrıldıktan sonra kapalı kapıları algılamak için renk bilgisine güvenen bir diğer çalışmada (DíazVilariño, Khoshelham, Martinez-Sanchez ve Arias, 2015) Hough dönüşümü kullanılarak kapalı kapılar aranmaktadır. Ancak bu çalıșma duvar düzlemi ve kapıya ait renk dağılımlarının farklı olması kısıtını içermektedir.

Kapalı kapıların bulunması amacıyla sadece nokta bulutu verisini kullanan yöntemler de geçmiş çalışmalarda sunulmuştur. Borgsen, Schöpfer, Ziegler ve Wachsmuth (2014) yaptıkları çalışmada noktaların normalleri gibi yapısal tanımlamaları kullanarak nokta bulutu verisinden kapalı kapıları ve kapı kolunu bulmayı amaçlamışlardır. İlk olarak, bölge büyütme algoritması ile bölütlenen bölgelerden nokta sayısı, yükseklik ve genişlik gibi özelliklere göre kapı adayları seçilir. Ardından, bulunan adaylar belirli ölçütlere göre olasılıksal tahminlerden geçer ve kapılar bulunur. Yapılan testlerde kullanılan veriler gerçek ortamdan ve yaklaşık olarak kapıların karşısından alınmıştır. Rusu, Meeussen, Chitta ve Beetz (2009) kapalı kapıları bulmak için lazer algılayıcı ile elde edilmiș nokta bulutu verisinden yararlanmışlardır. Gerçek zamanlı olarak kapı bulma algoritmasını çalıştırmak amacıyla nokta bulutu örneklenmiş daha sonra RMSAC ve bölge büyütme gibi bölütleme yöntemleri kullanılmıștır. Benzer bir yaklaşım Goron, Tamas ve Lazea (2012) tarafından da sunulmuştur. Bu yaklaşımlarda kapı panellerinin duvar düzleminden farklı derinlik seviyesinde olduğu varsayılmaktadır. Bayram ve diğ. (2019) yaptıkları çalıșmada, kapalı ve yarı açık kapıların nokta bulutu ile bulunması için bölge büyütme yöntemi ile duvarları bölütlemişlerdir. $\mathrm{Bu}$ noktada, RGB-D kameranın dar açılarda ve uzak mesafelerdeki çözünürlük problemini ele almak için parametre belirleme algoritması önermişlerdir. Duvar bölütlerinde kapalı kapı adaylarını belirledikten sonra boyut karşılaştırması parametre belirleme algoritmasından gelen değerler ile yapılmaktadır.

Nokta bulutu verisi kullanılarak açık kapıların bulunması ise çok farklı uygulama alanlarında karşımıza çıkabilmektedir. Örneğin, Derry ve Argall (2013) tekerlekli sandalyelerin otonom olarak kapıdan geçişi için standart kapı boyutlarını kullanarak açık kapı tanımlamaya çalışmışlardır. Kapı için duvar zemininde boşlukları arayan yöntemde, yatay olarak oluşturulan çizgilerde komşu nokta sayısına bakılarak kapı boşlukları bulunmaktadır. Ancak, duvar zeminleri bulunurken RANSAC algoritması kullanıldığı için yanlış düzlemler oluşmaktadır. Yazarlar, tek açık kapı için iki farklı test gerçekleştirmişlerdir. İlk testte kapılar cam duvarlarda bulunmakta ve kapı bulma oranı yaklaşık olarak \%84 olarak hesaplanmaktadır. İkinci testte ise normal duvarlar içindeki açık kapılar \%86 oranında bulunmuştur. Her iki testi de robot ile kapı arasındaki açı cinsinden değerlendirdiğimizde açı daraldıkça kapı bulma oranlarının $\% 60$ civarına düștüğü gözlemlenmektedir. Otonom robot keşif görevleri için Xu, Kim, Zhang ve Khosla (2015) önerdiği algoritma açık alan algılayıcı ve engelden kaçış modülünden oluşmaktadır. Bu çalışmada, nokta bulutu verisi voksel filtre ile örneklendikten sonra RANSAC ile duvarlar ve zemin ayrıștırılmaktadır. Nokta bulutundan ayrılan duvar düzleminde belirli bir yükseklikten yatay tarama yapılmaktadır. Bulunan boşluk belirli bir eşikten fazla ise potansiyel kapı olarak değerlendirilmektedir. Kapının çerçevesi çıkarılmayan yöntemde kapı genişliği ile uyan ve kapıya ait olmayan boşluklardan dolayı çok fazla yanlış negatif sonuç üretilmektedir. Souto, Castro, Gonçalves ve Nascimento (2017), robotların konumlandırılması için kapı ve merdivenleri doğal işaretçi olarak kullandıkları yaklaşımlarını, imge tabanlı derin öğrenme yaklaşımı ile karşılaştırmış ve daha iyi kapı tanıma oranlarına ulaşmışlardır. Bu yöntem, ilk olarak nokta bulutunu filtreden geçirerek nokta sayısı azaltmaktadır. Daha sonra RANSAC kullanılarak büyük düzlemler çıkarılmaktadır. Açık, yarı açık ve kapalı kapılar için geliştirilen yöntemde kenar noktalar bulunmuş ve bu noktaların konumlarına göre kapı ve merdivenler bulunmuştur. Önerilen yöntemin test edilmesi için robot ile kapı arasındaki açı 0 ve 45 derece seçilmiştir. 0 derece de kapı bulma oranı ortalama \%98,9 olurken 45 derece ile yapılan testlerde bu oran \%86'ya düşmüștür.

Binanın yașam döngüsü boyunca tüm bilgileri kaydeden ve binanın dijital ortamda bir temsili olan yapı bilgi modeli (Building Information Modeling BIM) üzerine yapılan çalışmalarda da açık kapı bulma işlemi yer almaktadır. Previtali, Díaz-Vilariño, ve Scaioni (2018) RANSAC kullanarak duvar, tavan ve taban gibi düzlemsel yüzeyleri çıkartmıştır. $\mathrm{Bu}$ çalışmada yazarlar, duvar düzlemi üzerinde ya da önünde yer alan nesnelerin kapı benzeri açıklıklar 
oluşturabileceğini belirtmişlerdir. $\mathrm{Bu}$ problemden dolayı ışın takibi yönteminden gelen görülebilirlik analizine göre doluluk ızgarası olușturulmaktadır. Buna ek olarak, $x$ ve y yönlerinde aynı hizalama ve takip eden nesneler arası uzaklıklar dikkate alınmaktadır. Ayrıca optimizasyon tabanlı yaklaşımda iç ortamlarda belirli bir düzene sahip kapı ya da pencere için şekil, hiza ve boşluk düzeni aranmaktadır. BIM üzerine geliştirilen bașka bir çalıșmada (Jung, Stachniss, Ju ve Heo, 2018), z ekseni boyunca histogram değerlerine göre duvar ve zemin ayrıldıktan sonra Douglas-Peuker bölütleme yöntemine ile kapı ve pencere için boş alanlar bulunmaktadır.

Staats, Diakité, Voûte ve Zlatanova (2019) yürünebilir uzayları keşfetmek için nokta bulutu verisi ile gezgin robotun ilerlediği yol bilgilerini kullanmışlardır. İlk olarak, nokta bulutu verisi voksel uzayına aktarılmaktadır. Böylece veriye uzamsal bir yapı sağlanmış ve miktarı azaltılmış olur. Kapıları algılamak için voksel yapıların ve yolun yatay ve dikey kontrolünün birleşimine güvenilmektedir. Robot belirlenen bir yol boyunca ilerlerken yatay ve dikey kontroller yapılarak kapılar bulunmaya çalışılır. Benzer bir çalışma Díaz-Vilariño, Verbree, Zlatanova ve Diakité (2017) duvar düzlemi bulunmadan ilk olarak kapı adayları aranmaktadır. Robotun ilerlediği yol boyunca nokta bulutunda dikey olarak profiller çıkarılmaktadır. Duvardaki açıklık olarak değerlendirilen kapı adayları içerdikleri nokta sayısına ve yatay düzlemdeki ortalama yüksekliğine göre bulunmaktadır.

Model tabanlı yaklașımların yanında derin öğrenme tabanlı yaklaşımlarda sunulmuştur. Bersan, Martins, Campos ve Nascimento (2018), CNN tabanl nesne algılama ve 3B model tabanlı bölütleme teknikleri ile farklı sınıflar tanımlanmış ve konumlandırılmıștır. Algılayıcı ile çevrenin 2B haritasını çıkaran SLAM, CNN ile nesne tanımlama modülü, nokta bulutu kullanarak nesne pozisyonlama gibi üç ana modülden oluşan yöntemde kapılar renk bilgisi kullanılarak eğitilen YOLO (Redmon, Divvala, Girshick ve Farhadi, 2016) modeli ile bulunmuştur.

$\mathrm{Bu}$ çalışmada önerilen yönteme benzer bir yaklaşım Yuan, Hashim, Zaki ve Huddin (2015) tarafından sunulmuş ve sadece RGB-D kameradan elde edilen derinlik haritasından yararlanılmıştır. Kapı kenarlarının sağında ve solunda yer alan piksel değerlerinde büyük farklar olacağı varsayımı kullanılmıştır. Bu farkların oluştuğu pikseller göz önüne alınarak derinlik imgesinde kapının dört köşe noktası belirlenmiştir. Önerilen yöntemin test edilmesi aşamasında kamera ve kapı arasındaki mesafe yaklaşık olarak 3,5m olarak seçilmiş ve kamera kapının tam karşısına konumlandırılmıştır.

Yapılan geçmiş çalışmalar incelendiğinde, uygulama alanları değişse bile çoğu çalışmada ilk olarak RANSAC ya da bölge büyütme gibi bölütleme yaklaşımları kullanılarak duvar düzlemlerinin belirlendiği görülmektedir. $\mathrm{Bu}$ yöntemler her zaman doğru bölütlemeler yapmadığından yanlış negatif tahmin oranını artırmaktadır. Ayrıca, bölütme için bir süre gerekmektedir. Bu noktada, yapılan çalışmaların çoğu hesaplama maliyetini azaltmak ve gerçek zamanlı uygulamalar için filtreler kullanarak nokta bulutundaki nokta sayısını azaltmaktadırlar. Diğer yandan, robotun izlediği yol ile birlikte kapı bulmaya çalışan yaklaşımlarda ise kapı konumuna çok yakın ya da kapı konumunda tanımlama işlemi yapılabilmektedir. Derin öğrenme tabanlı yaklaşımlar ise kapıları renk bilgisi kullanarak bulmaktadır. Tüm bu çalışmalar göz önüne alındığında, önerilen çalışma kural tabanlı olduğu ve bölütleme gerektirmediği için nokta sayısında herhangi bir indirgeme gerçekleştirmeden gerçek zamanlı çalışabilmektedir. Ayrıca, kapı konumları robotun kapıdan uzak olduğu durumlarda önceden belirlenebilmektedir. Son olarak, küresel koordinat sistemini temel aldığı için robotun kapının tam karşısında olmadığı durumlarda da çalışabilmektedir.

\section{Yöntem}

Önerilen yöntemde RGB-D kamera nokta bulutunun üretilmesi amacıyla kullanılmıștır. Bu kamera gördüğü sahneye ait renk bilgilerinin yanı sıra derinlik bilgisi de elde edebilmektedir. Sahnenin 3B nokta bulutu modeli 480x640 boyutlarındaki genişlik ve yükseklik ile elde edilen derinlik bilgisi kullanılarak olușturulmaktadır. 307200 adet noktadan oluşan bir nokta bulutu modelinde her noktanın $x, y$ ve $z$ koordinatları bulunmaktadır. Ayrica, bu nokta bulutu modeli 480x640 boyutunda düzenli bir yapıdadır. Önerilen yöntemde açık kapıların bulunması için nokta bulutu modeli kullanılacaktır. $\mathrm{Bu}$ model 3 temel aşamadan geçtikten sonra modelin temsil ettiği sahnede açık kapı bulunup bulunmadığına karar verilmektedir. Bahsedilen bu temel aşamalar bu bölümde detaylı olarak anlatılacaktır.

\subsection{Nokta Bulutunun Küresel Koordinat Sistemine Aktarılması}

Robotun üzerine yerleştirilen RGB-D kamera ile nokta bulutu verisi oluşturulurken robotun yerel koordinat sistemi temel alınmaktadır. Bununla birlikte, kural tabanlı kapı bulma yönteminde küresel koordinat sistemi kullanılacaktır. Böylece önerilen yöntemin robot ile kapı arasındaki açıdan bağımsız olarak çalışması amaçlanmıştır. Sonuç olarak, elde edilen ham nokta bulutunun küresel koordinat sistemine aktarılması gerekmektedir. Şekil 1(a)'da robotun yerel koordinat sistemine göre elde edilmiş ham bir nokta bulutu modeli gösterilmiştir. $\mathrm{Bu}$ şekilde küresel koordinat sistemi ise kırmızı, yeşil ve mavi renklerle gösterilmiştir. $\mathrm{Bu}$ renkler sırasıyla $\mathrm{x}, \mathrm{y}$ ve $\mathrm{z}$ eksenlerini 
temsil etmektedir. Ham nokta bulutu modeli z ekseni etrafında robotun yönelimi kadar saat yönünde döndürüldüğünde küresel koordinat sistemine aktarılmış hali elde edilmektedir (Şekil 1(b)).

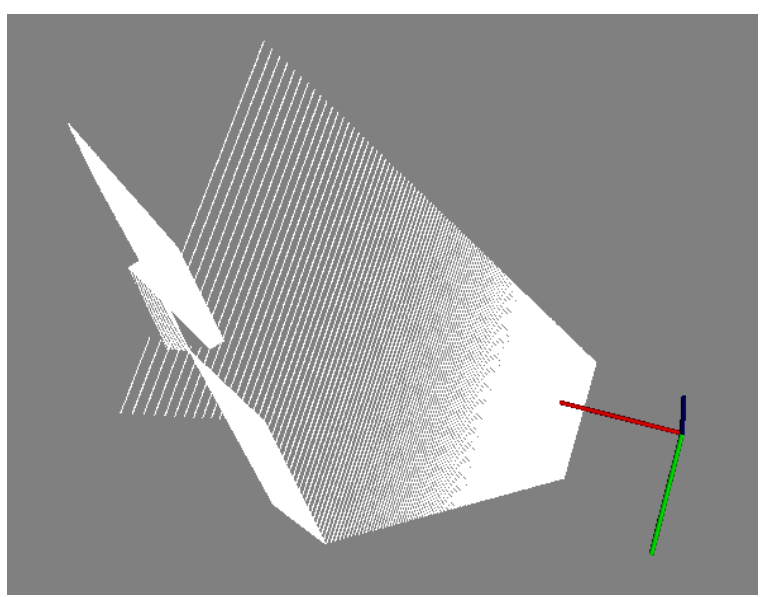

(a) Robotun Yerel Koordinat Sistemine Göre

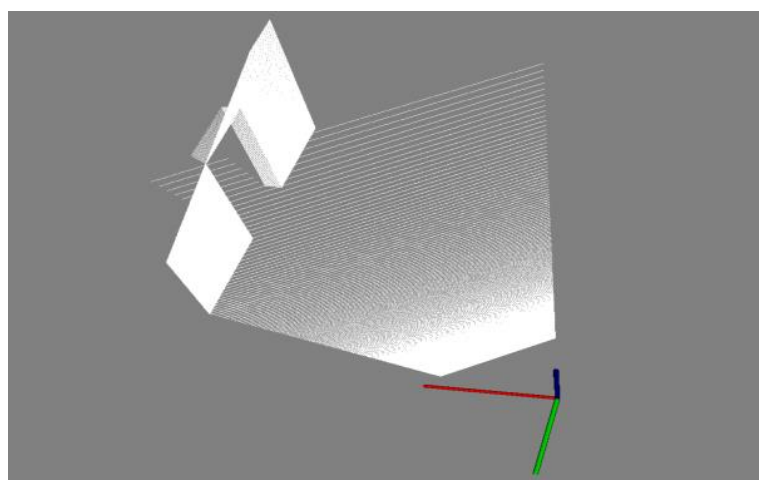

(b) Küresel Koordinat Sistemine Göre

Şekil 1. Örnek Nokta Bulutu Modeli

\subsection{Kapının Köşe Noktalarının Belirlenmesi}

$\mathrm{Bu}$ aşamada, küresel koordinat sistemine aktarılmış nokta bulutu modelinde kapının köșeleri olabilecek noktaları belirlemek için bir dizi kural kullanılarak arama yapılacaktır. Șekil 2'de belirlenmesi amaçlanan 4 köşe nokta ve küresel koordinat sistemi gösterilmektedir. Şekilde koordinat sistemindeki oklar artış yönünü ifade etmektedir. Aramanın başlayacağ köşe noktası robotun kapıya karşıdan baktığı durum düșünüldüğünde sol üstte yer alan köșe olarak varsayılmıştır. $\mathrm{Bu}$ varsayım tamamen rastsal olarak yapılmıştır ve diğer köșelerden birinin aramanın başlayacağı köşe olarak kullanılması önerilen yöntemin genel fikrini etkilememektedir. Bu köșe noktası Şekil 2'de 1 numara ile ifade edilmiştir. $\mathrm{Bu}$ noktanın belirlenmesi için nokta bulutunun 480x640 boyutundaki düzenli yapısından yararlanılmıştır. Bu düzenli yapı 2B bir dizi olarak düşünülebilir. RGB-D kamera bu dizideki her bir hücre için derinlik bilgisi ölçümü yapmaktadır. Eğer bir hücre için kameranın ölçüm mesafesi içinde bir engel yoksa ölçüm alınamamakta ve bu hücre boş olarak sınıflandırılmaktadır. Ayrıca bu hücreler nokta bulutu çıktısında gösterilmemektedir. Eğer bir hücre için ölçüm alınabiliyorsa bu hücre bir nokta ile temsil edilmekte ve dolu olarak sınıflandırılmaktadır. Şekil 2'deki 1 numaralı köșe dikkatle incelendiğinde noktanın solunda ve üstünde dolu hücrelerin sağında ve altında boş hücrelerin olduğu görülmektedir. $\mathrm{Bu}$ gözlem 1 numaralı köşe noktasının belirlenmesi için kullanılmaktadır. Nokta bulutunu temsil eden dizi içerisinde boş hücreler dolu hücrelere oranla çok daha az oldukları için aramayı hızlandırmak amacıyla boş olan hücreler bulunmaktadır. Bu hücrenin solundaki ve üstündeki hücreler dolu ve sağındaki ve altındaki hücreler boş ise bu nokta 1 numaralı köșe olarak kabul edilmektedir.

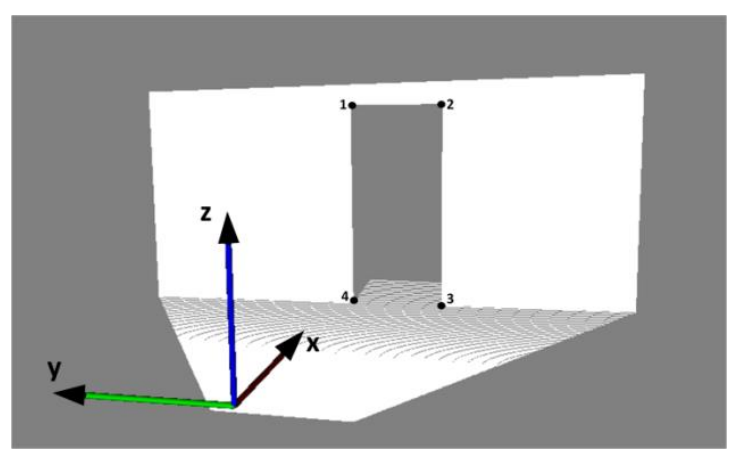

Şekil 2. Kapının Köşe Noktaları ve Küresel Koordinat Sistemi

Şekil 2'de görüldüğü üzere küresel koordinat sistemine aktarılmış nokta bulutunda duvar düzlemi y eksenine paralel olmaktadır. Robot ile kapı arasındaki açıdan bağımsız olarak bütün nokta bulutu verileri için bu durum geçerlidir. Köşe noktaların tespitinde bu bilgiden yararlanılmıștır. 2 numaralı köșe nokta incelendiğinde 1 numaralı köșe ile hemen hemen aynı $\mathrm{x}$ ve $\mathrm{z}$ koordinatlarına sahipken 2 numaralı köșenin $\mathrm{y}$ koordinatı 1 numaralı köşeye göre daha küçüktür. Ayrıca bu iki nokta hemen hemen aynı doğru parçası üzerinde bulunmaktadır. 2 numaralı köșe noktasının tespiti için 1 numaralı köşeden başlayan ve k-En yakın komşu algoritmasını (Altman,1992) kullanan bir arama yapılmaktadır. $\mathrm{Bu}$ aramada 1 numaralı köşenin $\mathrm{K}$ komșuluğuna bakılmaktadır. $\mathrm{K}$ komșu içinde 1 numaralı nokta ile $\mathrm{x}$ ve $\mathrm{z}$ koordinatları arasındaki fark belirli bir eşik değerin (DIST_THRESH) altında olan, y koordinatı 1 numaralı noktadan küçük olan ve y ekseninden x eksenine tanımlanan açı değeri en küçük olan nokta güncel nokta olarak belirlenmektedir. Benzer şekilde güncel noktanın K komşuluğu aynı kriterler kullanılarak arama ilerletilmektedir. Arama 
sonucunda kriterlere uyan herhangi bir nokta kalmadığında -y yönünde ilerlemenin sona erdiği anlaşılmaktadır. Bu noktada artık 2 numaralı köşe noktası belirlenmelidir. Bunun için son güncel noktanın $\mathrm{K}$ komşuluğu bu sefer $\mathrm{y}$ ve $\mathrm{z}$ koordinatları güncel noktanın y ve z koordinatlarından küçük olan en yakın nokta için araştırılmakta ve bulunan nokta 2 numaralı köşe olarak tanımlanmaktadır.

3 numaralı köşe noktasının belirlenmesi için 2 numaralı köșe noktasından başlayarak -z yönünde aramayı ilerletmek gerekmektedir. Dolayısıyla güncel nokta ile $\mathrm{x}$ ve $\mathrm{y}$ koordinatları arasındaki fark DIST_THRESH altında olan, $\mathrm{z}$ koordinatı güncel noktadan küçük olan ve $\mathrm{z}$ ekseninden $\mathrm{x}$ eksenine tanımlanan açı değeri en küçük olan nokta güncel nokta olarak belirlenmektedir. Bu arama sonucunda herhangi bir nokta bulunamadığında güncel noktanın $\mathrm{K}$ komşuluğu bu kez y koordinatı güncel noktanın y koordinatından büyük olan ve $\mathrm{z}$ koordinatı güncel noktanın $\mathrm{z}$ koordinatından küçük ya da eşit olan nokta için araştırılmakta ve bulunan nokta 3 numaralı köşe olarak tanımlanmaktadır.

4 numaralı köşe noktasının belirlenmesi için 3 numaralı köşe noktasından başlayarak +y yönünde aramayı ilerletmek gerekmektedir. Dolayısıyla güncel nokta ile $\mathrm{x}$ ve $\mathrm{z}$ koordinatları arasındaki fark DIST_THRESH altında olan, $y$ koordinatı güncel noktadan büyük olan ve $\mathrm{x}$ ekseninden $\mathrm{y}$ eksenine tanımlanan açı değeri en küçük olan nokta güncel nokta olarak belirlenmektedir. Bu arama sonucunda herhangi bir nokta bulunamadığında güncel noktanın $\mathrm{K}$ komşuluğu bu sefer $\mathrm{y}$ ve $\mathrm{z}$ koordinatları güncel noktanın y ve z koordinatlarından büyük olan en yakın nokta için araştırılmakta ve bulunan nokta 4 numaralı köşe olarak tanımlanmaktadır.

\subsection{Kapının Çerçevesinin Belirlenmesi}

Kapı konumuna ait olduğu düşünülen 4 köșe nokta belirlendikten sonra bu noktalar kullanılarak kapı adayının genişlik ve yükseklik değerleri hesaplanmaktadır. $\mathrm{Bu}$ değerler Türk Standartları Enstitüsünün (TS 9111, 2020) kapı için belirlediği boyutlara \pm olarak belirli bir eşik değeri (DOOR_THRESH) katılarak karar verilen sınırlar içinde kalıyorsa, bu 4 köşe nokta kapı konumuna aittir ve bu noktalar kullanılarak kapı konumunun çerçevesi çizdirilmektedir.

$\mathrm{Bu}$ çalışmada araştırma ve yayın etiğine uyulmuştur. Makalede yasal/özel izin alınması gerekmemektedir.

\section{4. “OGUROB KAPI” Veri Kümesi}

Önerilen yöntemin başarısını analiz etmek amacıyla OGUROB KAPI adı verilen veri kümesi ROS (2020) robot ara yüzü ve GAZEBO (2020) benzetim ortamı kullanılarak oluşturulmuştur. Pioneer P3-AT (2020) gezgin robotun üzerine yerleştirilen Asus Xtion Pro derinlik algılayıcı ile benzetim ortamında modellenen açık kapılardan nokta bulutu verileri toplanmıştır. Veri toplama aşamasında OpenCV ve PCL (Rusu ve Cousins, 2011) gibi görüntü ve nokta bulutu kütüphaneleri kullanılmıştır.

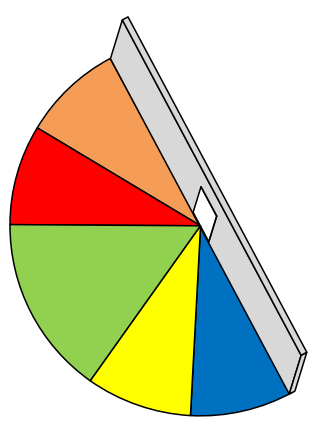

Şekil 3. Veri Kümesi Oluşturma Aşamasında Tanımlanan Bölgeler: Turuncu( $\left.0^{\circ}-30^{\circ}\right)$, kirmızı(30$\left.60^{\circ}\right)$, yeşil $\left(60^{\circ}-90^{\circ}\right), \operatorname{sarl}\left(120^{\circ}-150^{\circ}\right), \operatorname{mavi}\left(150^{\circ}-180^{\circ}\right)$

Geçmiş çalışmalarda genellikle robotun sadece kapının tam karşısında olduğu durumlar için testler yapılmıştır. Ancak, önerilen yöntem robotun kapı ile bulunabileği muhtemel bütün konumlar göz önüne alınarak test edilmek istenmektedir. Dolayısıyla oluşturulan veri kümesinde Şekil 3'te gösterilen 5 farklı bölgeden açık kapı içeren 42 adet nokta bulutu örneği bulunmaktadır. Turuncu ve mavi bölgelerde robot ile kapı arasındaki açı değeri sırasıyla $0^{0}-30^{0}$ ve $150^{0}-180^{\circ}$ arasındadır. Bu bölgelerin her birinde 5 adet açık kapıya ait nokta bulutu örneği alınmıştır. Kırmızı ve sarı bölgelerden 7'şer adet örnek bulunmaktadır. Bu bölgelerde robot ile kapı arasındaki açı sırayla $30^{\circ}-60^{\circ}$ ve $120^{\circ}-150^{\circ}$ arasındadır. Son olarak, yeşil bölgede robotun kapı ile arasındaki açı $60^{\circ}-120^{\circ}$ arasındadır ve bu bölgeden 18 adet nokta bulutu verisi elde edilmiștir. Şekil 4'te turuncu, kırmızı, yeşil, sarı ve mavi bölgelerden elde edilmiş veri örnekleri gösterilmektedir. Şeklin sol sütunda nokta bulutu verisi sağ sütununda ise RGB resimleri yer almaktadır. Elde edilen veri kümesinde yer alan nokta bulutu ve imge verilerine OGUROB KAPI (2020) açık adresinden ulaşılabilir.

\section{Deneysel Sonuçlar}

Önerilen yöntem OGUROB KAPI veri kümesi kullanılarak test edilmiş ve test sonuçları çalışma zamanı performansı ve kapı tanıma oranları açısından değerlendirilmiştir. Kapının köșe noktalarını belirlemek amacıyla gerçekleştirilen arama esnasında kullanılan k-En yakın komşu algoritmasında kullanılan K parametresi 200 olarak seçilmiştir. Aramanın aynı eksen üzerinde devam etmesini sağlayan 
DIST_THRESH eşik değeri parametresi 0,01 metre olarak belirlenmiştir. DOOR_THRESH parametresi 0,05 metre olarak kullanılmıştır. Ayrıca kapıların genişlik ve yükseklik değerleri için Türk Standartları Enstitüsünün (TS 9111, 2020) numaralı ve "Özürlüler ve hareket kısıtlılığı bulunan kişiler için binalarda ulaşılabilirlik gerekleri" isimli standardında yer alan $0,9 \mathrm{~m}$ ve $2,1 \mathrm{~m}$ kullanılmıştır. Testlerin gerçekleștirildiği bilgisayar Intel Xeon işlemciye ve 31,3 GiB geçici belleğe sahip olup Ubuntu 16.04 işletim sistemi ile çalıșmaktadır.
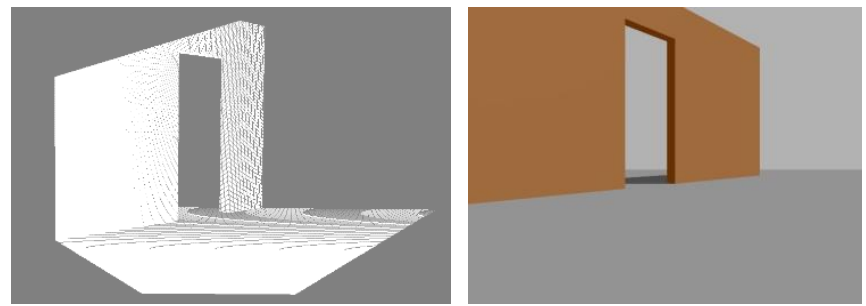

(a) Turuncu Bölge

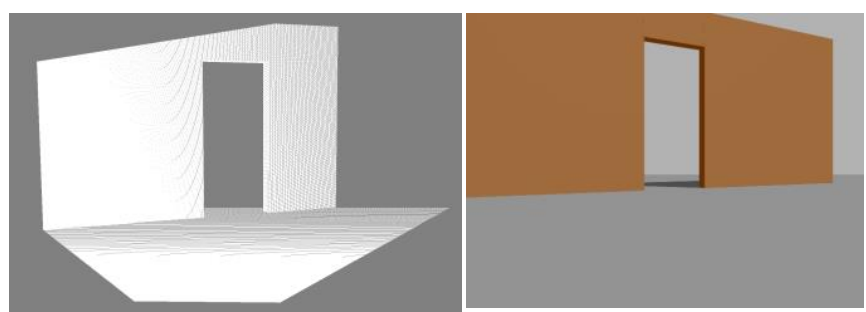

(b) Kırmızı Bölge
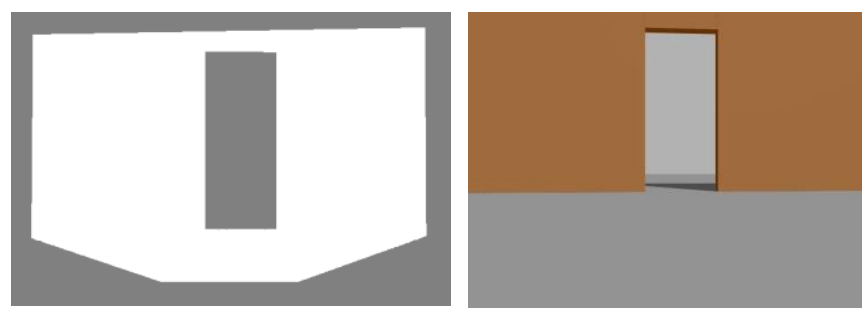

(c) Yeşil Bölge
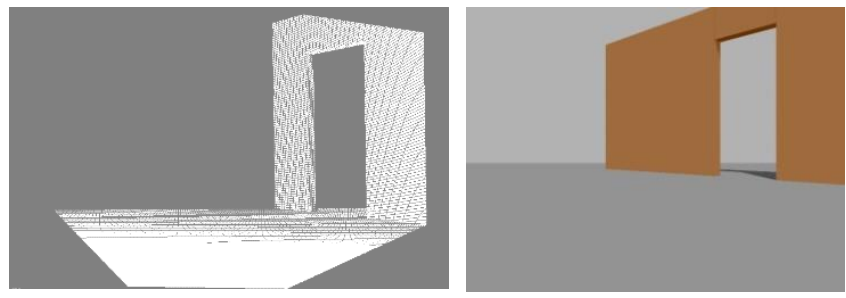

(d) Sarı Bölge
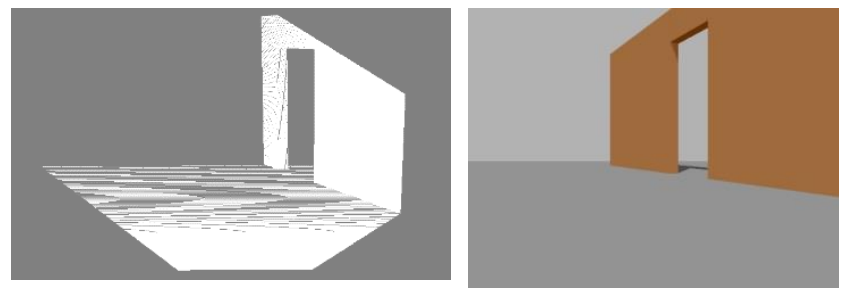

(e) Mavi Bölge
Şekil 4. OGUROB KAPI Veri Kümesinde Farklı Bölgelerden Alınan Örnekler

\section{1. Çalışma Zamanı Performansı}

Önerilen yöntemin zaman karmaşıklığı doğrusal, bir bașka deyișle $\mathrm{O}(\mathrm{n})$ olarak hesaplanmaktadır. Burada $n$ değeri nokta bulutunda bulunan nokta sayısını göstermektedir. Yöntem ilk olarak nokta bulutunu robotun yerel koordinat sisteminden küresel koordinat sistemine aktarmaktadır. Ardından, ilk köșe noktasının bulunmasında bütün noktalar taranmaktır. Dolayısıyla, bu aşamalarda bütün noktalar işlenmekte ve bu adımların maliyeti $O(n)$ olmaktadır. Diğer köşe noktalarının bulunmasında k-En yakın komşu algoritması $\mathrm{K}$ parametresi ile kullanılmaktadır. $\mathrm{Bu}$ yöntemde K, 200 gibi sabit ve küçük bir sayı olduğu için bu aşamanın zaman karmaşıklığı $O(K)$ ya da sabit zamanlı olarak ortaya çıkmaktadır. Sonuç olarak, O(n) bütün yöntemin zaman karmaşıklığını ifade etmektedir. OGUROB KAPI veri kümesinde bulunan 42 adet nokta bulutu verisinin ortalama kapı bulma süresi $10 \mathrm{~ms}$ olarak ölçülmüştür.

\subsection{Kapı Tanıma Oranı}

Önerilen yöntemin kapı tanıma oranı performansının irdelenmesi amacıyla yapılan testlerin sayısal sonuçları Tablo 1'de görsel sonuçları ise Şekil 5'te verilmiştir. Şekillerdeki mavi çerçeveler kapıların başarılı olarak tespit edildiği örneklerde çizdirilmiştir.

Tablo 1

OGUROB KAPI Veri Kümesi Sayısal Sonuçlar

\begin{tabular}{lccc}
\hline Bölge & $\begin{array}{c}\text { Doğru } \\
\text { Pozitif }\end{array}$ & $\begin{array}{c}\text { Yanlış } \\
\text { Pozitif }\end{array}$ & $\begin{array}{c}\text { Tanıma } \\
\text { Oranı }\end{array}$ \\
\hline Turuncu & 3 & 2 & $\% 60$ \\
Kırmızı & 6 & 1 & $\% 86$ \\
Yeşil & 18 & 0 & $\% 100$ \\
Sarı & 7 & 0 & $\% 100$ \\
Mavi & 4 & 1 & $\% 80$ \\
\hline Toplam & 38 & 4 & $\% 91$ \\
\hline
\end{tabular}

Önerilen yöntem robotun yerel koordinat sistemi yerine küresel koordinat sistemini kullandığı ve kapı bulmak için gerekli olan bir dizi kuralı bu koordinat sistemini temel alarak tanımladığı için teorik olarak robot ile kapı arasındaki açıdan bağımsız olması beklenmektedir. Ancak, Tablo 1 incelendiğinde robotun kapıyı dar açlardan gördüğü Turuncu ve Mavi bölgelerde kapı bulma oranının düştüğü görülmüştür. Bunun sebebi, robot ile kapı konumu arasındaki açı daraldıkça, RGB-D kameranın görüş açısı gittikçe daralmakta ve kapının tamamı nokta bulutu ile ifade 
edilememektedir. Bu durumda arama işlemi başarısız olmakta ve kapı konumu bulunamamaktadır. Şekil 5(a) ve Şekil 5(b)'de bu duruma örnekler gösterilmektedir. Diğer yandan, bu bölgelerden alınan nokta bulutu örneklerinde eğer kapının tamamı nokta bulutunda yer alıyorsa kapı başarılı bir şekilde bulunabilmektedir (Şekil 5(c) ve Şekil 5(d)). Sarı, Kırmızı ve Yeşil bölgelerde genellikle robot kapı konumuna geniş açıyla bakmakta ve kapının tamamı nokta bulutunda yer almaktadır. Dolayısıyla önerilen yöntem başarılı bir şekilde bu bölgedeki nokta bulutu verilerindeki kapı konumlarını belirleyebilmektedir.

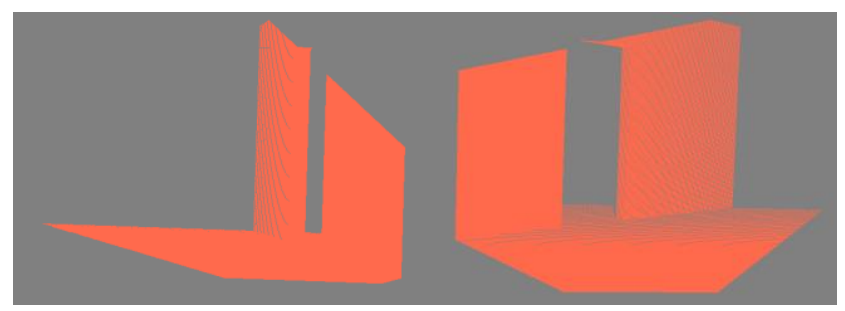

(a) Mavi Bölge - Başarısız

(b) Kırmızı Bölge - Başarısız

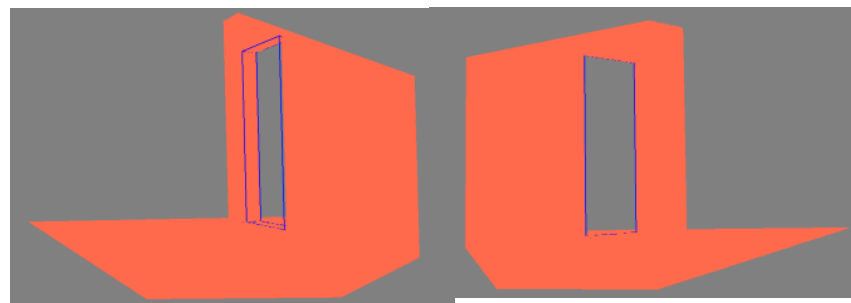

(c) Mavi Bölge - Başarılı

(d) Kırmızı Bölge - Başarılı

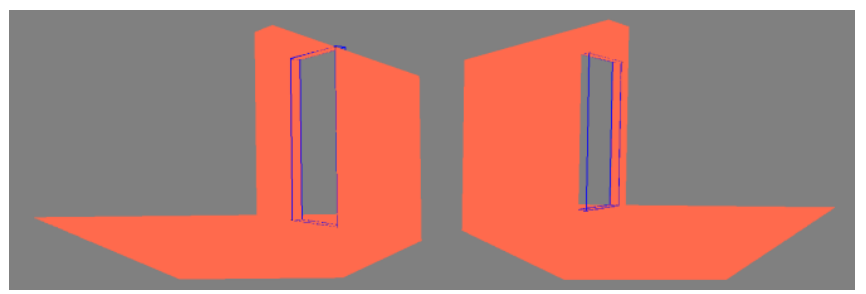

(e) Sarı Bölge - Başarılı

(f) Turuncu Bölge - Başarılı

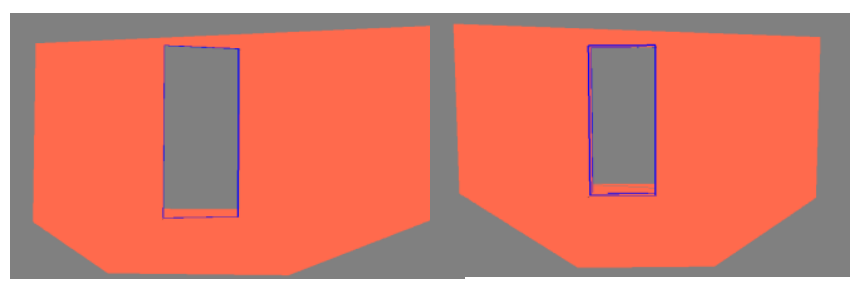

(g) Yeşil Bölge - Başarılı

(h) Yeșil Bölge - Başarılı

Şekil 5. OGUROB KAPI Veri Kümesi Görsel Sonuçlar

\section{Sonuçlar ve Gelecek Çalışmalar}

Bina içi ortamlarda açık kapıların belirlenmesi bir çok robotik uygulamasında çözülmesi gereken bir problemdir. Geçmiş çalışmalarda bu problemin çözümü için genellikle duvar düzlemi RANSAC ya da bölge büyütme gibi bölütleme yöntemleri ile bulunmakta ve daha sonra bu düzlem içinde açık kapı olup olmadığı araştırılmaktadır. Bu zaman alıcı ve eğer doğru bölütleme yapılamazsa kapı bulma performansını önemli ölçüde etkileyecek bir yöntemdir. Geçmiş çalışmaların bir diğer kısıtı ise robotun kapının tam karşısında ya da geniş açılarla gördüğü konumlarda kapı bulma yöntemlerinin başarılı olmasıdır. Önerilen yöntem geçmiş çalışmalardan farklı olarak robotun yerel koordinat sistemine göre elde edilen nokta bulutu verisini küresel bir koordinat sistemine aktarmaktadır. Ardından, kapı konumları küresel koordinat sistemine göre belirlenen bir dizi kural ile aranmaktadır. Böylece duvar düzleminin aranması gerek olmamakta ve yöntem, robot ile kapı arasındaki açıdan bağımsız olmaktadır. Önerilen yaklașımın kapı konumu belirlemesi için gerekli olan ortalama süre $10 \mathrm{~ms}$ olarak ölçülmüş ve gerçek zamanlı uygulamalar için uygun olabileceği gösterilmiştir. Ayrıca kapının tamamını gördüğü nokta bulutlarında başarılı bir şekilde çalıştığı yapılan testler ile gösterilmiştir. $\mathrm{Bu}$ testlerde toplam kapı bulma doğru pozitif oranı \%91 olarak hesaplanmıştır.

Gelecek çalışmalarda aramanın başlayacağı noktanın tespiti için 480x640 düzenli yapı yerine küresel koordinat sisteminin kullanılması planlanmaktadır. Böylece yöntem hem düzenli hem de düzensiz yapıdaki nokta bulutlarında çalışabilecektir. Ayrıca nokta bulutunda kapının tamamının gözükmediği durumlar göz önüne alınarak önerilen yöntemin geliştirilmesi planlanmaktadır.

\section{Araştırmacıların Katkısı}

$\mathrm{Bu}$ araștırmada; Burak KALECİ, literatür araştırması, yöntem geliștirilmesi, kodlanması ve test edilmesi; Kaya TURGUT, literatür araştırması, yöntem geliştirilmesi, kodlanması ve test edilmesi konularında katkı sağlamışlardır.

\section{Çıkar Çatışması}

Yazarlar tarafından herhangi bir çıkar çatışması beyan edilmemiştir.

\section{Kaynaklar}

Altman, N. S. (1992). An introduction to kernel and nearest-neighbor nonparametric regression. The American Statistician, 46 (3), 175-185. doi: $\underline{10.2307 / 2685209}$

Bayram, K., Kolaylı, B., Solak, A., Tatar, B., Turgut, K. ve Kaleci, B. (2019). 3B nokta bulutu verisi ile bölge büyütme tabanlı kapı bulma uygulaması. Türkiye Robotbilim Konferansı, 139-145, İstanbul, Türkiye. 
Bersan, D., Martins, R., Campos, M. \& Nascimento, E. R. (2018). Semantic map augmentation for robot navigation: a learning approach based on visual and depth data. Latin American Robotic Symposium, Brazilian Symposium on Robotics (SBR) and Workshop on Robotics in Education (WRE), 45-50, Joao Pessoa, Brazil.

Borgsen, S. M. Z., Schöpfer, M., Ziegler, L. \& Wachsmuth, S. (2014). Automated door detection with a 3Dsensor. Canadian Conference on Computer and Robot Vision, 276-282, Montreal, QC, Canada.

Derry, M. \& Argall, B. (2013). Automated doorway detection for assistive shared-control wheelchairs. IEEE International Conference on Robotics and Automation, 1254-1259, Karlsruhe, Germany.

Díaz-Vilariño, L., Khoshelham, K., Martinez-Sanchez, J. \& Arias, P. (2015). 3D modeling of building indoor spaces and closed doors from imagery and point clouds. Sensors, 15(2), 3491-3512. doi: https://doi.org/10.3390/s150203491

Díaz-Vilariño, L., Verbree, E., Zlatanova, S. \& Diakité, A. (2017). Indoor modelling from SLAM-based laser scanner: door detection to envelope reconstruction. The International Archives of the Photogrammetry, Remote Sensing and Spatial Information Sciences, 42, 345-352. doi: 10.5194/isprs-archives-XLII-2-W7345-2017

ElKaissi, M., Elgamel, M., Bayoumi, M. \& Zavidovique, B. (2006). SEDLRF: A new door detection system for topological maps. International Workshop on Computer Architecture for Machine Perception and Sensing, 75-80, Montreal, QC, Canada.

Jung, J., Stachniss, C., Ju, S. \& Heo, J. (2018). Automated 3D volumetric reconstruction of multiple-room building interiors for as-built BIM. Advanced Engineering Informatics, 38, 811-825. doi: https://doi.org/10.1016/j.aei.2018.10.007

Gazebo (2020). Robot simulation open source robotics foundation (OSRF). Erişim adresi: http://gazebosim.org/.

Goron, L. C., Tamas, L. \& Lazea, G. (2012). Classification within indoor environments using 3D perception. Proceedings of IEEE International Conference on Automation, Quality and Testing, Robotics, 400-405, Cluj-Napoca, Romania.

Hensler, J., Blaich, M. \& Bittel, O. (2010). Real-Time door detection based on adaboost learning algorithm. In: Gottscheber A., Obdržálek D., Schmidt C. (eds). Research and Education in Robotics. Communications in Computer and Information Science, 82, 61-73. doi: https://doi.org/10.1007/978-3-642-16370-8 6

Kakillioglu, B., Ozcan, K. \& Velipasalar, S. (2016). Doorway detection for autonomous indoor navigation of unmanned vehicles. IEEE International
Conference on Image Processing (ICIP), 3837-3841, Phoenix, AZ, USA.

Kaleci, B., Şenler, Ç. M., Dutagaci, H. \& Parlaktuna, O. (2015). Rule-based door detection using laser range data in indoor environments. IEEE 27th International Conference on Tools with Artificial Intelligence (ICTAI), 510-517, Vietri sul Mare, Italy.

Murillo, A. C., Košecká, J., Guerrero, J. J. \& Sagüés, C. (2008). Visual door detection integrating appearance and shape cues. Robotics and Autonomous Systems, 56(6), 512-521. doi: https://doi.org/10.1016/j.robot.2008.03.003

OGUROB KAPI (2020). Erişim adresi: http://www.airobotlab.ogu.edu.tr/OGUROB KAPI.html.

Pioneer P3-AT (2020). Erișim adresi: http://www.ist.tugraz.at/attach/Publish/Kmr06/p ioneer-robot.pdf.

Previtali, M., Díaz-Vilariño, L. \& Scaioni, M. (2018). Towars automatic reconstruction of indoor scenes from incomplete point clouds: door and window detection and regularization. International Archives of the Photogrammetry, Remote Sensing and Spatial Information Sciences, XLII-4, 507-514. doi: https://doi.org/10.5194/isprs-archives-XLII-4-507$\underline{2018}$

Quintana, B., Prieto, S. A., Adán, A. \& Bosché, F. (2018). Door detection in 3D coloured point clouds of indoor environments. Automation in Construction, 85, 146-166. doi: 10.1016/j.autcon.2017.10.016

Redmon, J., Divvala, S., Girshick, R. \& Farhadi, A. (2016). You only look once: Unified, real-time object detection. IEEE Conference on Computer Vision and Pattern Recognition (CVPR), 779-788, Las Vegas, NV, USA.

ROS (Robot Operating System) (2020). Open source robotics foundation (OSRF). Erişim adresi: http://ros.org/.

Rusu, R. B. \& Cousins, S. (2011). 3D is here: point cloud library (PCL). IEEE International Conference on Robotics and Automation, 1-4, Shanghai, China.

Rusu, R. B., Meeussen, W., Chitta, S. \& Beetz, M. (2009). Laser-based perception for door and handle identification. International Conference on Advanced Robotics, 1-8, Munich, Germany.

Staats, B., Diakité, A., Voûte, R. \& Zlatanova, S. (2019). Detection of doors in a voxel model, derived from a point cloud and its scanner trajectory, to improve the segmentation of the walkable space. International Journal of Urban Sciences, 23(3), 369390. doi: $\underline{10.1080 / 12265934.2018 .1553685}$

Souto, L. A. V., Castro, A., Gonçalves, L. M. G. \& Nascimento, T. P. (2017). Stairs and doors recognition as natural landmarks based on clouds of 3D edge-points from RGB-D sensors for mobile robot localization. Sensors, 17(8). doi: $10.3390 / \mathrm{s} 17081824$ 
TS 9111 “Özürlüler ve hareket kısıtlılığı bulunan kişiler için binalarda ulaşılabilirlik gerekleri” Kabul Tarihi: 22.11.2011.

Meeussen, W., Wise, M., Glaser, S. \& Chitta., S. (2010). Autonomous door opening and plugging in with a personal robot. IEEE International Conference on Robotics and Automation, 729-736, Anchorage, AK, USA.

Xu, J., Kim, K., Zhang, L. \& Khosla, D. (2015). 3D perception for autonomous robot exploration. In: Bebis G. et al. (eds) Advances in Visual Computing. ISVC 2015. Lecture Notes in Computer Science, 9474, 888-900. doi: https://doi.org/10.1007/978-3-319$\underline{27857-579}$

Yang, X. \& Tian, Y. (2010). Robust door detection in unfamiliar environments by combining edge and corner features. IEEE Computer Society Conference on Computer Vision and Pattern Recognition Workshops (CVPRW), 57-64, San Francisco, CA, USA.

Yuan, T. H., Hashim, F. H., Zaki W. M. D. W. \& Huddin, A. B. (2015). An automated 3D scanning algorithm using depth cameras for door detection. International Electronics Symposium (IES), 58-61, Surabaya, Indonesia. 